\title{
PENGARUH FILM PENDEK TERHADAP KEMAMPUAN MENULIS CERPEN SISWA KELAS X SMA NEGERI 2 PANGSID
}

\author{
Kamalia $^{1}$, Rustam Efendy R. ${ }^{2}$, Suardi Zain ${ }^{3}$, Nuraini Kasman ${ }^{4}$ \\ 1, 2, 3,4 Universitas Muhammadiyah Sidenreng Rappang \\ Jl. Angkatan 45 No 1A Lautang Salo Rappang, Pancarijang, Sidenreng Rappang \\ kamalia-17@gmail.com
}

\begin{abstract}
Abstrak: Pengaruh Film Pendek terhadap Kemampuan Menulis Cerpen Siswa Kelas X SMA Negeri 2 Pangsid. Penelitian ini bertujuan untuk memperoleh data dan informasi yang lengkap tentang Pengaruh Media Film Pendek terhadap Kemampuan Menulis Cerpen Siswa Kelas X SMA Negeri 2 Pangsid Kabupaten Sidenreng Rappang pada tahun pelajaran 2015/2016. Populasi dan sampel berjumlah 51 siswa. Data dikumpulkan melalui teknik dokumentasi dan teknik tes. Data dianalisis menggunakan aplikasi SPSS 21.0 for windows. Nilai mean pretest sebesar 55,68 dengan kategori kurang, sedangkan nilai mean posttest sebesar 79,5098 dengan kategori baik. Nilai $p$-value lebih kecil daripada $\alpha(0,000<0,050)$. Hal tersebut menandakan bahwa $\mathrm{H}_{0}$ ditolak dan $\mathrm{H}_{1}$ diterima. Ini berarti bahwa ada pengaruh penggunaan film pendek terhadap kemampuan menulis cerpen.
\end{abstract}

Kata kunci : film pendek, media, menulis cerpen.

\begin{abstract}
The Influence of Short Films on the Ability to Write Short Stories for Class X Students of SMA Negeri 2 Pangsid. This study aims to obtain about the effect of short film media on the ability to write short stories for class X students of SMA Negeri 2 Pangsid, Sidenreng Rappang Regency in the 2015/2016 academic year. Population and sample amounted to 51 students. Data were collected through documentation techniques and test techniques. Data were analyzed using the SPSS 21.0 for windows application. The mean pretest value was 55.68 in the poor category, while the mean posttest was 79.5098 in the good category. The p-value is smaller than $\alpha(0.000<0.050)$. This indicates that $\mathrm{H}_{0}$ is rejected and $\mathrm{H}_{1}$ is accepted. This means that there is an effect of using short films on the ability to write short stories.
\end{abstract}

Keywords: media, short film, writing short story.

Pengajaran apresiasi sastra pada dasarnya mencakup pengajaran prosa, puisi dan drama. Dalam pengajaran prosa terbagi atas dua bagian yaitu prosa imajinatif (rekaan) dan prosa imajinatif (bukan rekaan). Prosa menurut bentuknya terbagi atas roman, novel, cerpen. Akan tetapi, yang menjadi kajian utama dalam tulisan ini adalah cerpen. Di dalam karya sastra prosa (cerpen) terdapat unsur intrinsik yaitu tema, alur, karakter, setting, sudut pandang, dan gaya bahasa. Sedangkan yang termasuk unsur ekstrinsik meliputi latar belakang kehidupan pengarang, keyakinan dan pandangan hidup pengarang, adat istiadat yang berlaku saat itu, situasi politik, persoalan sejarah, ekonomi, pengetahuan agama.

Pembelajaran menulis cerpen membutuhkan inovasi yang mampu meningkatkan hasil belajar siswa (Ecca et al., 2020; Ecca \& Lanta, 2019; Palupi, Pratiwi, \& Suherjanto, 2013). Media memegang 
peranan penting dalam pembelajaran bahasa Indonesia. Dengan media yang sesuai, siswa dapat menangkap penjelasan dari guru dengan mudah. Begitu juga dalam pembelajaran menulis cerpen, yaitu dengan menggunakan "film pendek" sebagai medianya. Dengan media "film pendek" diharapkan pembelajaran menulis cerpen lebih efektif dan siswa dapat dengan mudah menuangkan ide-ide atau imajinasinya ke dalam sebuah karya sastra yaitu cerpen dan dapat menghasilkan tulisan cerpen yang baik.

Penggunaan media film pendek diterapkan dalam pembelajaran menulis cerpen pada siswa kelas X SMA Negeri 2 Pangsid. "Film pendek" yang memiliki durasi waktu relatif singkat diharapkan dapat dijadikan sebagai media yang efektif dan sesuai dengan pembelajaran menulis cerpen dikelas. Dengan melihat film, siswa akan terpengaruh dan lebih antusias dalam mengikuti pembelajaran. Selain itu, karena "film pendek" tidak memerlukan waktu yang lama, sehingga waktu pembelajaran dapat disesuaikan dengan alokasi waktu dalam pembelajaran. Media tersebut diharapkan dapat efektif untuk diterapkan dalam pembelajaran menulis cerpen di kelas. Maka, perlu adanya penelitian untuk menguji sejauh mana efektivitas media "film pendek" dalam pembelajaran menulis cerpen. Agar "film pendek" dapat dijadikan media yang tepat dan efektif untuk meningkatkan minat dan kemampuan menulis cerpen siswa

\section{METODE}

Variabel penelitian ini ada dua variabel yaitu media film pendek dan kemampuan menulis cerpen. Media film pendek merupakan alat bantu proses belajar mengajar yang dapat memiliki durasi minimal 50 menit. Kemampuan menulis cerpen merupakan kesanggupan seseorang dalam menuangkan isi hatinya ke dalam cerita pendek yang dipengaruhi oleh latar belakang penulis. Penelitian ini tidak menggunakan kelas kontrol sebagai bahan pembandingnya. Desain penelitian digunakan peneliti one group pretest-postttest design. Data dikumpulkan melalui teknik dokimentasi dan tes. Selanjutnya dianalisis menggunakan aplikasi SPSS 21 berupa mean dan $p$-value.

\section{HASIL DAN PEMBAHASAN}

Hasil penelitian ini berupa data skor tes awal dan data skor test akhir menulis cerpen. Data skor test awal diperoleh dari hasil pretest kemampuan menulis cerpen tanpa menggunakan media film pendek dan data skor akhir diperoleh dari hasil posttest kemampuan menulis cerpen dengan menggunakan media film pendek.

Tabel 1 Perolehan nilai siswa kelas X SMA Negeri 2 Pangsid Kabupaten Sidenreng Rappang

\begin{tabular}{ccc}
\hline Nilai & Pre Test & Post Test \\
\hline 100 & - & - \\
\hline 90 & - & 16 \\
\hline 85 & - & 1 \\
\hline 80 & 2 & 18 \\
\hline 70 & 9 & 13 \\
\hline 60 & 16 & 3 \\
\hline 50 & 13 & - \\
\hline 40 & 11 & - \\
\hline$\Sigma$ & 51 & 51 \\
\hline
\end{tabular}

Sumber: Hasi tes

Tabel 1 menunjukkan bahwa nilai tertinggi pada pretest adalah nilai 80 dan nilai terendah adalah 40 , Sedangkan nilai terteinggi pada posttest adalah 90 dan nilai terendah adalah 60 .

Tabel 2 Nilai Mean dan Standar Deviasi dari Pre-test dan post-test siswa kelas $X$ SMA Negeri 2 Pangsid Kabupaten Sidenreng Rappang

\begin{tabular}{ccc}
\hline & Rata-rata (mean) & Standard deviasi \\
\hline Pre-test & 55,68 & 11,35 \\
\hline Pos-test & 79,50 & 9,06 \\
\hline Sumber: Hasil olah SPSS 21.0 &
\end{tabular}

Sumber: Hasil olah SPSS 21.0

Tabel 2 menunjukkan bahwa nilai mean pretest 55,68 yang diklasifikasikan dalam kategori "Kurang", sedangkan nilai mean posttest 79,50 yang diklasifikasikan dalam kategori "Baik". Dan standar deviasi dari pretest 11,35 , sedangkan standar deviasi dari posttest 9,06. 
Tabel 3 P-value Pretest dan Posttest siswa

\begin{tabular}{ccc}
\hline Variabel & $\alpha$ & p-value \\
\hline Pretest-posttest & 0,005 & 0,000 \\
\hline Sumber: Hasil olah SPSS 21.0 &
\end{tabular}

Tabel 3 menunjukkan bahwa p-value lebih kecil daripada $\alpha(0,000<0,05)$. Hal tersebut menandakan bahwa $\mathrm{H}_{0}$ ditolak, dan $\mathrm{H}_{1}$ diterima. Ini berarti bahwa ada perbedaan signifikan antara menggunakan media film pendek terhadap kemampuan menulis cerpen siswa kelas X SMA Negeri 2 Pangsid Kabupaten Sidrap. Oleh karena itu, disimpulkan bahwa penggunaan media film pendek berpengaruh terhadap kemampuan menulis cerpen siswa kelas X SMA Negeri 2 Pangsid Kabupaten Sidenreng Rappang. Hasil penelitian ini didukung oleh Arsyad (2009: 49) yang mengemukakan bahwa film pendek sebagai bahan pengajaran menulis cerpen pada umumnya digunakan untuk tujuan hiburan, dokumentasi, pendidikan, dan proses belajar mengajar. Terutama media ini dapat menyajikan informasi, memaparkan proses, menjelaskan konsep yang rumit, mengajarkan keterampilan, dan mempengaruhi sikap seseorang.

\section{PENUTUP}

Hasil penelitian ini menyimpulkan bahwa $\mathrm{H}_{0}$ ditolak, dan $\mathrm{H}_{1}$ diterima. Dengan demikian, bahwa penggunaan media film pendek berpengaruh terhadap kemampuan menulis cerpen siswa kelas X SMA Negeri 2 Pangsid Kabupaten Sidenreng Rappang. Oleh karena itu, disarankan agar menggunakan media yang bervariasi dalam pembelajaran menulis cerpen, salah satunya media film pendek. Penelitian sebelumnya juga menyimpulkan bahwa media film pendek efektif digunakan dalam pembelajaran menulis cerpen (Safitri, 2017; Agustina, Drs. Gde Artawan, \& I Made Astika, 2015;

\section{DAFTAR PUSTAKA}

Agustina, K. A., Drs. Gde Artawan, M., \& I Made Astika, S. (2015). Penggunaan Film Pendek untuk Meningkatkan Kemampuan Menulis Cerpen Kelas IX A SMP Negeri 1 Gerokgak. Jurnal Pendidikan Bahasa dan Sastra Indonesia Undiksha, 1-12.

Ecca, S., \& Lanta, J. (2019). Penggunaan Teknik Teratai dalam Menulis Puisi. Seminar Nasional Bahasa Indonesia 1, 1(November 2018), 486-492.

Ecca, S., Lanta, J., \& Aswadi, A. (2020). Desain Perencanaan dan

Pembelajaran Menulis Puisi di SMP. Seminar Nasional Bahasa Indonesia 2, 2 (October), 195-200.

Palupi, R. M., Pratiwi, Y., \& Suherjanto, I. (2013). Film Pendek sebagai Media untuk Meningkatkan Pembelajaran Menulis Cerpen berdasarkan Pengalaman Orang Lain di Kelas X-4 SMAN 02 Batu. Malang: S1 Program Studi Pendidikan Bahasa Sastra Indonesia dan Daerah.

Safitri, R. Z. (2017). Keefektifan Strategi Double Entry Journals Berbantuan Media Film Pendek dalam Pembelajaran Menulis Cerpen pada Siswa Kelas X SMA Negeri 1 Depok. E-Journal Pendidikan Bahasa dan Sastra Indonesia , 546-554. 